\title{
Prevention and control of contaminants of industrial processes and pesticides in the poultry production chain
}

\author{
C.A. KAN
}

ID TNO Animal Nutrition, P.O. Box 65, 8200 AB Lelystad, The Netherlands, e-mail: c.a.kan@idtno.nl

The reduction in levels of organochlorine pesticide residues in food of animal origin in the past 30 years has been achieved especially by controlling entrance via the feed chain. A further reduction was achieved by registration and use of less persistent pesticides both for direct treatment of animals and of plant material.

The remaining problems (e.g. dioxins and PCB's) are much harder to tackle. They are either of a ubiquitous nature and their impact might be enlarged by the present welfare trend requiring more contact of the animals with their environment, or they are of a sporadic nature making checking and control quite hard to execute. The present public demand for a farm animal production that is in balance with the animals' needs and a residue free product adds even more complications to the system.

Key words: contaminants; residues; poultry

\section{Introduction}

Prevention and control are the two key elements of the $\mathbf{H}$ (azard) $\mathbf{A}$ (nalysis) $\mathbf{C}$ (critical) $\mathbf{C}$ (ontrol) $\mathbf{P}$ (oint) approach. Currently in many different industrial processes this approach is favoured in producing safe foods for human consumption. Prevention requires knowledge about the origin of the problem and what to do about it. Control is not just monitoring but also influencing the situation. A nice example is the production of dry egg powder free of Salmonella. On many occasions during the production process one can check the Salmonella content e.g. at entrance of the raw material (the eggs), after breaking, at packing the dry powder, during storage or transport or at the shelf of the retailer. However, there is only one point in the process where one can really control it and that is in the drying step, where temperature and duration of stay can diminish or eliminate all Salmonella present.

\footnotetext{
"This paper was first presented at the 13th European Symposium on Poultry Nutrition in Blankenberge, Belgium, September 30th - October 4th, 2001."
} 
Prevention and control of contaminants and pesticides in the poultry production chain, requires:

1. Knowledge of the sources of contamination and their consequences and

2. Knowledge of possibilities to exclude these sources from the system or to reduce their effect.

The consequences of contamination in the poultry production chain have been recognised already many years ago and in 1979 at the 2nd European Symposium on Poultry Nutrition attention was already paid to this subject (Kan and Jonker - den Rooyen, 1979).

The ways to reduce uptake of contaminants by poultry or to reduce levels in the final product have been discussed before (Kan, 1994). These ways do not seem to be very (cost) effective and generally measures taken to prevent a problem are preferred over "end of pipe" curative measures.

Possible sources of contaminants and pesticides in the poultry production chain are feed, water, air, soil and environment. The causes can be deliberate use of $e . g$. pesticides on the crops, the animals or the building. Environmental pollution by e.g. PCBs, polychlorinated dioxins and dibenzofurans (see Figure 1 ) will have its impact on residue levels in poultry as well. Last but not least, as proven by the Belgian dioxin crisis, accidents in the feed supply chain can have an enormous impact on animal production.

Figure 1 The general structures of the polychlorinated dibenzo-p-dioxins, polychlorinated dibenzofurans, and polychlorinated biphenyls.

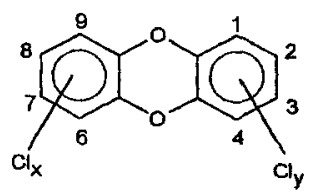

Polychlorinated Dibenzo-p-Dioxin

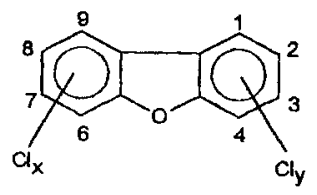

Polychlorinated Dibenzofuran

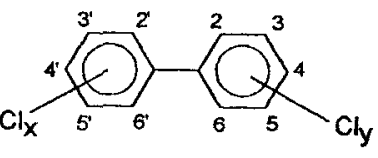

Polychlorinated Biphenyls

This paper will review firstly the different sources of contamination and the impact they may have on residues in the poultry products. Secondly special attention will be paid especially to the dioxins: their sources and the contribution of poultry products to the average daily intake through the human diet in Europe.

\section{Sources of pesticides and contaminants}

Organochlorine containing compounds (pesticides, PCBs, dioxins, dibenzofurans) have proven to be metabolically stable. This property explains their effectiveness when used in a field situation as well as their long lasting and unwanted residues in all environmental compartments.

The main sources, which will be discussed, are:

- Feed and feed ingredients

- Direct application to animals

- Environment, housing, soil, air

First the (organochlorine) pesticides will be discussed and secondly the contaminants. 


\section{Organochlorine pesticides in feed}

Residues of organochlorine pesticides in poultry and eggs due to their presence in feedstuffs have already been the subject of research for a long time. The available knowledge in 1978 could be summarised as follows (Kan, 1978):

1. Levels in abdominal fat and yolk of some pesticides like HCB, DDT and Dieldrin can considerably exceed levels in feed

2. Considerable differences in persistence exist between pesticides, lindane and methoxychlor being much less persistent than HCB or DDT.

Schenck and co-workers (Schenck and Donoghue, 2000), using more sophisticated methodology, confirmed that methoxychlor did not show residues in egg yolk after dosing hens.

Toxaphene, an organochlorine containing pesticide made up out of more than 600 individual components, may however remain a problem. Toxaphene has been banned for use from the western world for about 20 years but due to its possible use in other areas of the world and its persistence it still might be (or become) a problem. Schwind and coworkers (Schwind and Kaltenecker, 2000) using modern analytical techniques determined that some components show considerable carry over from feed to eggs. The half life time of these components in eggs was found to be between 25 and 42 days, which is in the same range as some of the organochlorine pesticides (Kan, 1978).

Generally, the prevention and control of organochlorine pesticides via the feed chain is adequate as shown by the considerable reduction in residues in poultry products over the period 1975-1995 (Kan, 1996). Both the ban on and reduction in use of organochlorine pesticides on many crops all over the world and the legislation and control of pesticides in feedstuffs and feeds have contributed to this decline.

\section{Organochlorine pesticides in the environment}

Malathion, a well-known ectoparasiticide, could not be recovered (Schenck and Donoghue, 2000) from the egg after dosing laying hens. However, dosing hens with chlorpyriphos-methyl and dimethoate did result in measurable quantities of these substances in the egg. Disappearance from the eggs after dosing was rapidly as could be expected with these substances, which are metabolically much less stable than the traditional organochlorine pesticides. Similarly Barnekow and his group (Barnekow et al., 2001) reported a very high excretion of (metabolites of) 2,4-dichlorophenoxyacetic acid $(2,4 \mathrm{D})$ by laying hens and very low amounts in their tissues. Bargar and his group (Bargar et al., 2001) injected $\alpha$ - or $\beta$-endosulfan into laying hens and found a very low excretion of the compounds or endosulfan sulfate via eggs.

Fishwick and co-workers (Fishwick et al., 1980) reported that both continuous and discontinuous operation of vaporisers with lindane in a layers house will lead to quite substantial lindane residue levels in eggs and abdominal fat. Exposure via the air is thus quite possible and should not be neglected as a contamination source of volatile and fatsoluble compounds.

\section{Contaminants in feed and housing}

Pentachlorophenol, previously widely used as wood preservative may cause residues in animals both via the oral route (Butler and Frank, 1991) or by absorption through the skin (Qiao et al., 1997). In the past, woodshavings used as bedding material were the main 
cause of pentachlorophenol residues in broilers and layers. Next to that, there was the microbial metabolism of pentachlorophenol into chlorinated anisoles, which occasionally caused very distinctive musty off-flavours in broiler meat and eggs (Land, 1975); (Steverink and Jansen, 1979). The half-life time of these components, however, is rather short, so if a contamination occurs, the elimination from the body can be a matter of days. Reduction in use of PCP by the timber industry has been the major cause for its declining importance as a contaminant in poultry production in Western Europe.

The present trend towards more contact with "natural" materials, being part of improved welfare for the animals, increases the risk animals getting in contact with wood containing a range of unwanted substances over an extended period of time. Waiting for a washout might not be an option then.

Coatings of concrete silo's, vapour seals or insulation material have proven also to be a possible contamination source for PCB residues in food of animal origin (Willett et al., 1985); (Hansen et al., 1989). These - sporadic - sources might seem to be of less importance than the straightforward feed contamination routes. However, if we succeed in better controlling the concentrated point sources of contamination or accumulation like fats used in animal nutrition, the percentage contribution of sporadic or widespread contaminations will increase.

Grob and his group (Grob et al., 2001) recently draw attention to contamination of eggs and animal fat with olefins and $n$-alkanes due to the assumed incorporation of mineral oil or paraffin oil into animal feed. This misuse was also brought in conjunction with the Belgian PCB crisis where "oil" was mixed into fat intended for incorporation in animal feed as an energy source. They clearly showed the presence of these non-natural components in food from animal origin.

\section{PCB from feed to product}

Fries and his group in Beltsville (Fries et al., 1977) gave feed with Arochlor 1221, 1232, $1242,1248,1254$ or 1268 to laying hens during 9 weeks and determined with (at that time) standard packed column GLC the residues in egg, body fat and excreta. The higher the chlorination rate to the biphenyls was (thus the higher the Arochlor number) the higher the PCB residues in eggs. The maximal transfer to body fat seemed to be at $54 \%$ chlorination (thus Arochlor 1254). The amount in excreta was about $10 \%$ of intake for all mixtures tested. The methodology used did not allow making a distinction between the individual components of the PCB mixtures in the Arochlor. Hansen and co-workers (Hansen et al., 1983) gave a feed with Arochlor 1254 either directly or after passage through pigs to broilers for about 20 days. They assessed the concentrations of 18 individual chlorobiphenyls in liver and body fat. Highest accumulation in body fat was found for the congeners $118,128,138,153$ and 180. Levels in liver followed a similar trend but there were some differences between isomers. Brunn (Brunn, 1984) gave radioactive congener 49 to laying hens and measured excretion of radioactivity in both eggs and excreta. About $42 \%$ of the dose was excreted as a metabolite in eggs and faeces. The rate of metabolism of the tetrachlorobiphenyl congener 49 is in the same order as metabolism of a number of organochlorine pesticides (Kan, 1977). Ueberschär and Vogt (Ueberschär and Vogt, 1986) determined the accumulation ratios of the congeners $28,52,101,135,153$ and 180 in broilers and layers. Congeners 52 and 101 showed much less persistence than the other four. Very recently Bargar and his group (Bargar et al., 2001) injected a pentachlorobiphenyl (congener 105), and hexachlorobiphenyl (congener 156) and a heptachlorobiphenyl (congener 189) into laying hens and measured residues in eggs. Transfer to egg was inversely correlated to chlorination rate but were all around $0.5 \%$ of 
the injected dose. Co-administration of other chemicals somewhat influenced excretion rate into eggs. Hoogenboom et al. (unpublished results, 2001) fed diluted feed originating from the Belgian dioxin crisis for one week to laying hens and broilers and followed residue patterns in egg and abdominal fat during several weeks, both with a biological (CALUX) test and with GC/MS. The PCB pattern in this feed is quite alike a 50/50 mixture of Aroclors 1254 and 1260 (van Larebeke et al., 2001). The results are not yet completely available, but of the seven marker components congener 101 proved to be much more metabolised than congeners $118,138,153$ and 180 . Congeners 28 and 52 were also metabolised quite extensively as can be expected for these lower chlorinated congeners. These results concur with the comparison of congener patterns in feed and eggs from Belgium in 1999 (van Larebeke et al., 2001).

\section{Dioxins and dibenzofurans from feed to product}

Zabik and her group (Zabik et al., 1998) fed a low level of 2,3,7,8- tetrachlorodibenzo-pdioxin (TCDD) to male leghorn chicks for 14 days. Residues of the dioxin were not found in brain, heart, fat, plasma, muscle kidney and skin. Residues were only found in liver samples even 21 days after the administration had stopped. Inclusion of mineral oil in the diet did not fasten the excretion of the TCDD. One can however wonder how the results would have been in much faster growing broiler type chickens. Hoogenboom et al (unpublished results 2001) found that 2,3,7,8 TCDD was only a minor component (about $1.5 \%$ of total dioxins and dibenzofurans) in the feed originating from the Belgian dioxin crisis. The major contributor to the TEQ-level by far (ca. 68\%) was 2,3,4,7,8Pentachlorodibenzofuran (PeCDF); other major components ( $>5 \%$ ) were 2,3,7,8-TCDF, $1,2,3,4,7,8-\mathrm{HxCDF}$ and 1,2,3,7,8-PeCDD. Similar results from other feed analyses have very recently published (van Larebeke et al., 2001). The levels in eggs and fat after cessation of administration naturally decreased due to excretion with the eggs, but the 4 above-mentioned congeners were about equally stable. The percentage contribution to the total residue slightly increased during the washout period. The overall picture from these studies is, that the higher chlorinated congeners are metabolically more stable and accumulate to a higher extent. However, also between congeners with the same chlorination rate there are considerable differences.

\section{Dioxins and dibenzofurans in the environment and the product}

Dibenzofurans and dioxins are ubiquitously present in our environment, but point sources due to fires involving chlorinated compounds occur. The resulting contamination of soil, water and air with dibenzofurans and dioxins often results in increased levels of these compounds in poultry products as well as in other fatty products. Chang and co-workers (Chang et al., 1989) e.g. showed that in after a fire involving a pentachlorophenol wood treatment plant in the Oroville $\mathrm{Ca}$, USA, eggs and chicken fat raised in that neighbourhood showed increased dibenzofuran and dioxin levels. A more detailed study on the situation in the area was published recently (Harnly et al., 2000). The absolute levels in soil and eggs did not change over a six-year period. Differences in residue level between sites of investigation were large. The major contributors to the TEQ amount were pentachlorophenol (PCP), octachlorodioxin (OCDD) and 1,2,3,4,6,7,8 HpCDD. A similar study in the UK - The Pantegg project - was published some years ago (Lovett et al., 1998a; Lovett et al., 1998b). Controlled exposure studies using contaminated soil incorporated in poultry diets were also carried out in relation to the US contamination findings (Stephens et al., 1990); (Petreas et al., 1991); (Stephens et al., 1995). Schuler and 
co-workers (Schuler et al., 1997) carried out a similar study in Switzerland. Both studies showed that intake of contaminated soil will increase the levels of contaminants in eggs or body fat although the bioavailability of the bound residues in soil is quite low. Pentachlorophenol treated wood in itself has also proven to be a source of dioxins and dibenzofurans in products of animal origin, especially milk and body fat of calves. (Fries et al., 1999); (Feil et al., 2000). Poultry that is provided with wood to increase their welfare might therefore pick up traces of dioxins or dibenzofurans, if this wood happens to be treated with chlorine containing compounds. Exclusion of these types of compounds for wood treatment is the main preventive action possible.

Biotransfer rates or accumulation ratios of organochlorine containing compounds in poultry products have still to be determined experimentally. The predictions made for transfer of these compounds into beef and milk using the molecular connectivity index (Dowdy et al., 1996) have to my knowledge not been tested yet for other farm animal species. The bio-availability of dioxins and dibenzofurans from "Kieselrot" has been compared in several in vitro systems (Wittsiepe et al., 2001). Unfortunately, the different systems gave quite different results, so a good predictor for in vivo data was not obtained.

\section{Dioxins and dibenzofurans in feedstuffs in the EU}

In November 2000, the Scientific Committee on Animal Nutrition of the EU has published an extensive report, summarising and evaluating all available data (Nutrition, 2000). Important conclusions were:

- Fish meal and fish oil of European origin are the most heavily contaminated feedstuffs

- Fish meal from the South Pacific is much less contaminated

- Animal fat is next in the order of dioxin concentration

- Other plant feed material is generally not heavily contaminated

- Levels in roughages and soil very much depend on local pollution and can vary enormously

- Bioavailability of dioxins and dibenzofurans in soil is generally low, so their contribution to residues in products of animal origin will be limited.

\section{Dioxins and dibenzofurans in food of animal origin}

Dioxin, dibenzofuran and pentachlorophenol levels in food of animal origin have been determined long ago. The data on Canadian samples of chicken and pork (Ryan et al., 1985) might not pass the 2001 standards for analytical methodology, but they indicated quite a substantial (background) contamination of about $50 \%$ of the chicken fat samples containing detectable amounts of dioxins and PCP. Goldman and co-workers (Goldman et $a l ., 1989)$ measured in the earlier mentioned Oroville area dioxin levels in food and levels in plasma of residents from that area. Dioxin levels were increased in both types of samples as compared to a non-exposed control area. Fries reviewed some years ago (Fries, 1995) the significance of animal food products as potential pathways for human exposure to dioxins from an American perspective. He concluded the following: "The potential for public concern over exposure to dioxins is high and regulatory actions to reduce emission of dioxins into the environment and food chains can be expected. Alterations in production practices or recommendations for dietary change do not seem realistic because of the diversity and uncertainties of the exposure pathways. Changes in animal production practices to reduce dioxin transmission to animal food products would require increased confinement of animals and greater use of concentrates. These practices are antithetical 
to the current emphasis on animal welfare and sustainable agriculture". Hecht has more recently (Hecht, 2000) tried to quantify the real contribution of meat and meat products to the dioxin intake of the German population. He estimates that the contribution is "only" $13 \%$ as opposed to the earlier assumption of a contribution of $30 \%$. There were however clear regional differences in residue levels, the western part of the country having the highest levels and the southern part showing the lowest levels.

The messages from these two papers seem - at first - contradictory; part of the difference may be due to the different situation of animal farming in the USA as opposed to Germany and the different approach taken by the authors. Part of the difference might also be due to a further decrease in dioxin levels in food of animal origin in the last few years. This decrease might both be real due to reduction in levels or perceived due to better - unbiased - sampling and improved analytical techniques.

The next difficult task is however to translate residue levels of the different components found into health hazards for the human population. The SCAN paper (Nutrition, 2000) has given a lot of attention to that for dioxins and dibenzofurans as well as e.g. Hansen in two papers (Hansen, 1987), (Hansen, 1998) did for toxicity assessment of PCB congeners.

A last point is the possible reduction in the levels of dioxins and dibenzofurans in meat and meat products, when found (too) high. Petroske and co-workers (Petroske et al., 1998) showed that these fat soluble compounds during frying end up in the pan fats and juices. So only if these are discarded, a reduction in residue levels can be obtained. Kan some years earlier (Kan, 1994) formulated a similar conclusion for organochlorine pesticides in poultry meat and eggs.

\section{Conclusion}

Prevention and control of organochlorine pesticides in feedstuffs and feeds has considerably reduced the levels in both feed and products in the past 30 years. The present challenge is to achieve a similar success on the environmental contaminants, where on one hand occurrence is quite ubiquitous - so hardly controllable - and on the other hand quite sporadic so also hard to control. To make life even more complicated, public opinion does not longer accept residues as "unavoidable" in the product. Consumers demand no residues and no risks on those issues where they themselves have apparently no control.

\section{Acknowledgement}

I want to thank B.P.M. Janszen for his constructive remarks on the draft manuscript.

\section{References}

BARGAR, T.A., SCOTT, G.I. and COBB, G.P. (2001) Maternal transfer of contaminants: Case study of the excretion of three polychlorinated biphenyl congeners and technical-grade endosulfan into eggs by white leghorn chickens (gallus domesticus). Environmental Toxicology and Chemistry 20: 61-67.

BARNEKOW, D.E., HAMBURG, A.W., PUVANESARAJAH, V. and GUO, M. (2001) Metabolism of 2,4dichlorophenoxyacetic acid in laying hens and lactating goats. Journal of Agricultural and Food Chemistry 49: 156-163.

BRUNN, H. (1984) Elimination and distribution of 2,2',4,5'-tetrachlorobiphenyl in laying hens. Food and Chemical Toxicology 22: 689-691.

BUTLER, K.M. and FRANK, R. (1991) Pentachlorophenol residues in porcine tissue following preslaughter exposure to treated wood shavings. Journal of Food Protection 54: 448-450. 
CHANG, R., HAYWARD, D.G., GOLDMAN, L.R., HARNLY, M.E. and FLATTERY, J. (1989) Foraging farm animals as biomonitors for dioxin contamination. Chemosphere 19: 481-486.

DOWDY, D.L., MCKONE, T.E. and HSIEH, D.P.H. (1996) Prediction of chemical biotransfer of organic chemicals from cattle diet into beef and milk using the molecular connectivity index. Environmental Science and Technology 30: 984-989.

FEIL, V.J., HUWE, J.K., ZAYLSKIE, R.G., DAVISON, K.L., ANDERSON, V.L., MARCHELLO, M. and TIERNAN, T.O. (2000) Chlorinated dibenzo-p-dioxin and dibenzofuran concentrations in beef animals from a feeding study. Journal of Agricultural and Food Chemistry 48: 6163-6173.

FISHWICK, F.B., HILL, E.G., RUTTER, l. and WARRE, P.R. (1980) Gamma-HCH in eggs and poultry arising from exposure to thermal vaporisers. Pesticide Science 11: 633-642.

FRIES, G.F. (1995) A review of the significance of animal food products as potential pathways of human exposures to dioxins. Journal of Animal Science 73: 1639-1650.

FRIES, G.F., LILLIE, R.J., CECIL, H.C. and BITMAN, J. (1977) Retention and excretion of polychlorinated biphenyl residues in laying hens. Poultry Science 56: 1275-1280.

FRIES, G.F., PAUSTENBACH, D.J., MATHER, D.P. and LUKSEMBURG, W.J. (1999) A congener specific evaluation of transfer of chlorinated dibenzo- $p$-dioxins and dibenzofurans to milk of cows following ingestion of pentachlorophenol-treated wood. Environmental Science and Technology 33: 1165-1170.

GOLDMAN, L.R., HAYWARD, D.G., FLATTERY, J., HARNLY, M.E., PATTERSON, D.G., NEEDHAM, L.L., SIEGEL, D., CHANG, R., STEPHENS, R.D. and KIZER, K.W. (1989) Serum, adipose and autopsy tissue PCDD and PCDF levels in people eating dioxin contaminated beef and chicken eggs. Chemosphere 19: 841-848.

GROB, K., VASS, M., BIEDERMANN, M. and NEUKOM, H.P. (2001) Contamination of animal feed and food from animal origin with mineral oil hydrocarbons. Food Additives and Contaminants 18: 1-10.

HANSEN, L.G. (1987) Food chain modification of the composition and toxicity of polychlorinated biphenyl (PCB) residues. Review in Environmental Toxicology 3: 149-212.

HANSEN, L.G. (1998) Stepping backward to improve assessment of PCB congener toxicities. Environmental Health Perspectives 106: 171-189.

HANSEN, L.G., SULLIVAN, J.M., NEFF, C.C., SANDERS, P.E., LAMBERT, R.J., BEASLEY, V.R. and STORR-HANSEN, E. (1989) Polychlorinated biphenyl contamination of domestic turkeys from building materials. Journal of Agricultural and Food Chemistry 37: 135-139.

HANSEN, L.G., TUINSTRA, L.G.M.T., KAN, C.A., STRIK, J.J.T.W.A. and KOEMAN, J.H. (1983) Accumulation of chlorobiphenyls in chicken fat and liver after feeding Aroclor 1254 directly or fat from swine fed Aroclor 1254. Journal of Agricultural and Food Chemistry 31: 254-260.

HARNLY, M.E., PETREAS, M.X., FLATTERY, J. and GOLDMAN, L.R. (2000) Polychlorinated dibenzo$p$-dioxin and polychlorinated dibenzofuran contamination in soil and home-produced chicken eggs near pentachlorophenol sources. Environmental Science and Technology 34: 1143-1149.

HECHT, H. (2000) Dioxinaufnahme der Deutschen Bundesbürger durch Fleisch und Fleischerzeugnisse. Fleischwirtschaft 80: 75-79.

KAN, C.A. (1977) Short-term balance studies of some organochlorine pesticides in poultry. Industrial and Environmental Xenobiotics Excerpta Medica International Congres Series (J.R. Fouts and I.Gut eds) 440: 208-210.

KAN, C.A. (1978) Accumulation of organochlorine pesticides in poultry: A review. Joumal of Agricultural and Food Chemistry 26: 1051-1055.

KAN, C.A. (1994) Factors affecting absorption of harmful substances from the digestive tract of poultry and their level in poultry products. World's Poultry Science Journal 50: 39-53

KAN, C.A. (1996) Residues in poultry products from Western Europe; detection, occurrence and control. Proceedings XX Worlds Poultry Science Association Congress New Delhi 3: 85-96.

KAN, C.A. and JONKER - DEN ROOYEN, J.C. (1979) The consequences of the carry over of pesticides in poultry. Proceedings 2 nd European Symposium on Poultry Nutrition (C.A. Kan and P.C.M. Simons eds.), 8587.

LAND, D.G. (1975) The origin and microbial and sensory consequences of chlorophenol contamination of broiler houses. Proceedings 2 nd European Symposium on Poultry Meat Quality (B. Erdtsieck ed.), paper 32 , $38 \mathrm{pp}$.

LOVETT, A.A., FOXALL, C.D., BALL, D.J. and CREASER, C.S. (1998a) The Panteg monitoring project: Comparing PCB and dioxin concentrations in the vicinity of industrial facilities. Journal of Hazardous Materials 61: 175-185.

LOVETT, A.A., FOXALL, C.D., CREASER, C.S. and CHEWE, D. (1998b) PCB and PCDD/DF concentrations in eggs and poultry meat samples from known urban and rural locations in wales and england. Chemosphere 37: 1671-1685.

PETREAS, M.X., GOLDMAN, L.R., HAYWARD, D.G., CHANG, R.R., FLATTERY, J.J., WIESMÜLLER, T., STEPHENS, R.D., FRY, D.M., RAPPE, C., BERGEK, S. and HJELT, M. (1991) Biotransfer and bioaccumulation of PCDD/PCDFs from soil: Controlled exposure studies of chickens. Chemosphere 23: 1731-1741. 
PETROSKE, E., ZAYLSKIE, R.G. and FEIL, V.J. (1998) Reduction in polychlorinated dibenzodioxin and dibenzofuran residues in hamburger meat during cooking. Journal of Agricultural and Food Chemistry 46: 3280-3284.

QIAO, G.L., BROOKS, J.D. and RIVIERE, J.E. (1997) Pentachlorophenol dermal absorption and disposition from soil in swine: Effects of occlusion and skin microorganism inhibition. Toxicology and Applied Pharmacology 147: 234-246.

RYAN, J.J., LIZOTTE, R., SAKUMA, T. and MORI, B. (1985) Chlorinated dibenzo-p-dioxins, chlorinated dibenzofurans and pentachlorophenol in Canadian chicken and pork samples. Journal of Agricultural and Food Chemistry 33: 1021-1026.

SCHENCK, F.J. and DONOGHUE, D.J. (2000) Determination of organochlorine and organophosphorous pesticide residues in eggs using a solid phase extraction cleanup. Journal of Agricultural and Food Chemistry 48: 6412-6415.

SCHULER, F., SCHMID, P. and SCHLATTER, C. (1997) The transfer of polychlorinated dibenzo-p-dioxins and dibenzofurans from soil into eggs of foraging chicken. Chemosphere 34: 711-718.

SCHWIND, K.J. and KALTENECKER, M. (2000) Toxaphen in Fleisch und Eiern, ein Mögliches Importiertes Rückstandsproblem. Fleischwirtschaft 80: 71-74.

SCIENTIFIC COMMITTEE ON ANIMAL NUTRITION OF THE EU (2000) Dioxin contamination of feedingstuffs and their contribution to the contamination of food of animal origin.

STEPHENS, R.D., HARNLY, M.E., HAYWARD, D.G., CHANG, R.R., FLATTERY, J., PETREAS, M.X. and GOLDMAN, L.R. (1990) Bioaccumulation of dioxins in food animals ii: Controlled exposure studies. Chemosphere 20: $1091-1096$.

STEPHENS, R.D., PETREAS, M.X. and HAYWARD, D.G. (1995) Biotransfer and bioaccumulation of dioxins and furans from soil: Chickens as a model for foraging animals. Science of the Total Environment 175: 253-273.

STEVERINK, A.T.G. and JANSEN, J. (1979) Chloorfenolen in houtstrooisel en mufheid in slachtgevogelte en eieren. Voedingsmiddelentechnologie 12: 24-27.

UEBERSCHÄR, K.H. and VOGT, H. (1986) Geflügelversuche zur Bestimmung der Anreicherungsfaktoren für PCB-Einzelkomponenten in Geweben und Eiern. VDLUFA Schriftenreihe 20 KongreBband, 641-655.

VAN LAREBEKE, N., HENS, L., SCHEPENS, P., COVACI, A., BAEYENS, J., EVERAERT, K., BERNHEIM, J.L., VLIETINCK, R. and DE POORTER, G. (2001) The Belgian PCB and dioxin incident of January-June 1999: Exposure data and potential impact on health. Environmental Health Perspectives 109: 265-273.

WILLETT, L.B., LIU, T.T.W., DURST, H.I., CARDWELL, B.D. and RENKIE, E.D. (1985) Quantification and distribution of polychlorinated biphenyls in farm silos. Bulletin of Environmental Contamination and Toxicology 35: 51-60.

WITTSIEPE, J., SCHREY, P., HACK, A., SELENKA, F. and WILHELM, M. (2001) Comparison of different digestive tract models for estimating bioaccessibility of polychlorinated dibenzo-p-dioxins and dibenzofurans from red slag 'kieselrot'. International Journal of Hygiene and Environmental Health 203: 263-273.

ZABIK, M.J., POLIN, D., UNDERWOOD, M., WIGGERS, P. and ZABIK, M.E. (1998) Tissue residues in male chickens fed a $50 \mathrm{ng} / \mathrm{kg}$ dietary concentration of 2,3,7,8-tetrachlorodibenzo-p-dioxin. Bulletin of Environmental Contamination and Toxicology 61: 664-668. 